\title{
Sonopartogram versus conventional partogram for monitoring progress of labor: a prospective observational study
}

\author{
Mohamed S. Sweed ${ }^{1 *}$ (D) Ihab F. Allam¹, Sherif A. Ashoush ${ }^{1}$, Osama A. Marwan ${ }^{2}$ and Eman A. NasrEIDin ${ }^{3}$
}

\begin{abstract}
Background: Repeated digital vaginal examination during labor may be uncomfortable for women and increases the risk of ascending infection. Transperineal ultrasound can assess fetal head descent, position, and cervical dilatation without these side effects. This study was conducted to evaluate the accuracy of transperineal ultrasound in monitoring labor progress.

Results: The study included 40 primigravida women in labor. Fair correlation was found between the assessment of fetal head station by vaginal examination (VE) and fetal head perineal distance (HPD) by transperineal ultrasound (TPUS) (Kendall's tau-b $(\tau)=-0.299,95 \% \mathrm{Cl}=-0.479$ to $-0.0863, p$ value $=.0063$ ) (Spearman rho $=-.3844, p$ value $\left.=.0143 ; r^{2}=0.1478\right)$. Strong correlation was found between the cervical dilatation assessed by VE and by TPUS (Pearson's $r=.8601,95 \% \mathrm{Cl}=0.7493$ to $0.9240, p$ value $<.0001, r^{2}=0.7396$ ). There is moderate agreement between VE and TPUS as regards the assessment of head position on the face-clock [weighted kappa $(\kappa)=.557$, $95 \% \mathrm{Cl}=.362$ to.753]
\end{abstract}

Conclusion: Transperineal ultrasound can be used as an alternative to repeated digital examination for assessment of labor progress.

Keywords: Labor, Vaginal delivery, Partogram, Sonopartogram

\section{Background}

The standard assessment method for labor progress worldwide is by digital vaginal examination (VE), where physicians can assess fetal head descent and position together with cervical effacement and dilatation. Still, assessment of cervical dilatation by VE might be imprecise $[1,2]$ and alterations in findings might cause distress to women and decrease their confidence in their care providers [3].

Repeated VE increases the risk of ascending infection and chorioamnionitis and shortens the latent period in women with premature rupture of membranes [4]. National Institute for Health and Clinical Excellence

\footnotetext{
* Correspondence: drmsweed@med.asu.edu.eg

'Department of Obstetrics and Gynecology, Ain Shams University, Cairo, Egypt

Full list of author information is available at the end of the article
}

(NICE) encouraged conduction of research to decrease frequency of VE during labor [5].

Transperineal ultrasound (TPUS) has been investigated as a complementary tool for management of labor [6]. Studies have demonstrated high reliability of TPUS for assessment of cervical dilatation and fetal head position and station [7-10]. Authors have suggested using TPUS alone when VE is not desirable as in cases with premature rupture of membranes or preterm labor [11]. TPUS was found to be more accepted and convenient to pregnant females than VE [12].

Conventionally, findings of VE are recorded on the partogram, a printed chart used worldwide for fetal and maternal monitoring during labor [4]. Hassan et al. introduced a novel, ultrasound-based chart, the sonopartogram for assessment of progress of labor and feto-maternal monitoring in desirable cases [11]. In 
spite of the promising results suggested, this sonopartogram has not been widely accepted.

This study was conducted to evaluate the accuracy of transperineal ultrasound in monitoring labor progress and to validate the use of the sonopartogram.

\section{Methods}

This prospective observational study was conducted during the period from December 2018 till October 2019. The study was approved by the institutional Ethical and Research Committee. The study included 40 primigravida women $>18$ years old, pregnant at $\geq 37$ and $<41$ weeks, single intrauterine pregnancy with vertex presentation, and during the active stage of labor (cervix 4-10 $\mathrm{cm}$ dilated). An informed written consent was obtained from all participants.

These women received the standard monitoring of labor, where VE was performed every $2 \mathrm{~h}$ by the obstetrician who recorded the cervical dilatation (in centimeters) and head station and position and plotted the findings onto conventional partogram together with the other routine parameters included as maternal vital data and fetal heart rate. Fetal head descent (station) was described according to WHO classification as the relationship of the vertex in centimeters above or below the ischial spines $(-5$ to +5$)$ [13]. Measurements were rounded up or down to the nearest whole centimeters, with a measurement at precisely 0.5 being rounded up. Fetal head position was determined based on the position of the posterior fontanel, according to a 12-h clock

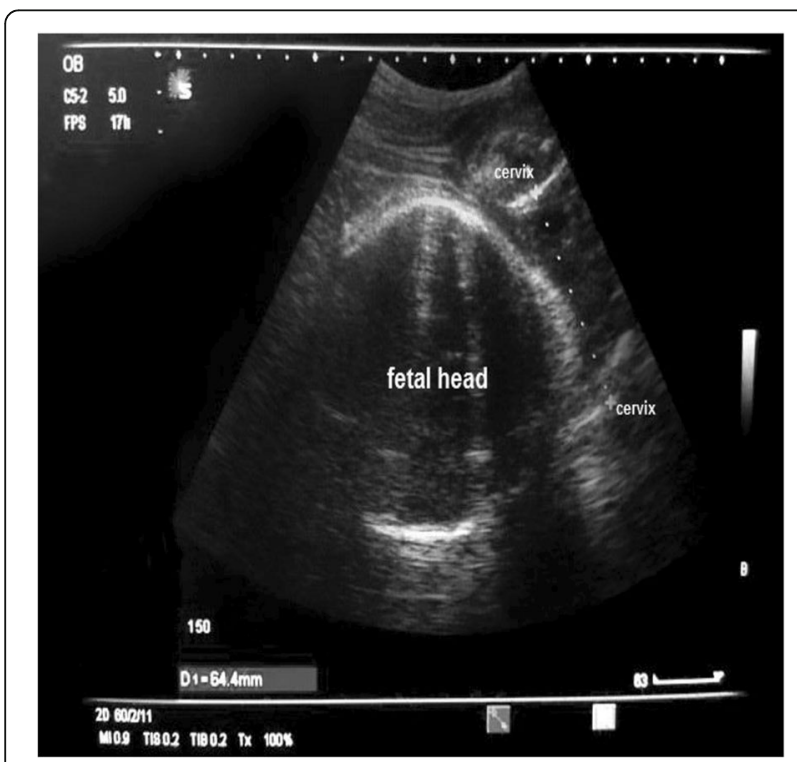

Fig. 1 Cervical dilatation measured by TPUS. Cervical dilatation is $64.4 \mathrm{~mm}$ measured transperineally in the anteroposterior plane from the inner part of the cervical tissue anteriorly and the inner part of the cervical tissue posteriorly

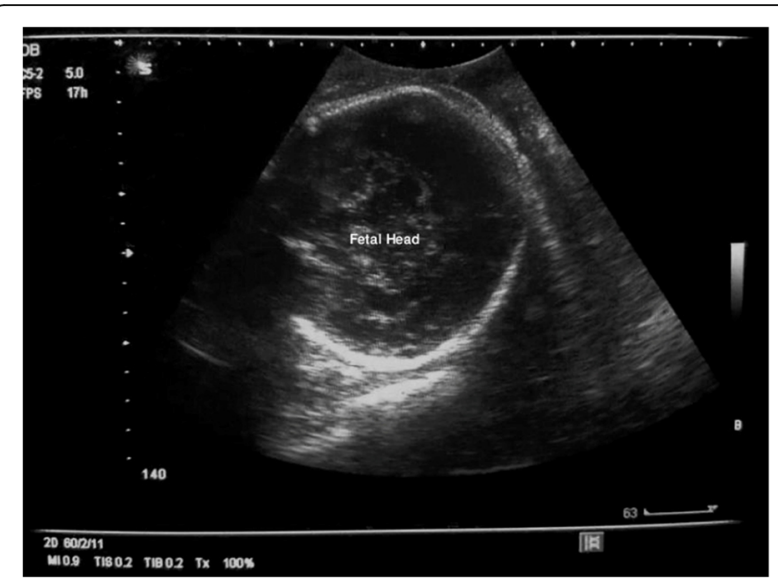

Fig. 2 Fully dilated cervix shown by TPUS. TPUS showing no cervical tissue to be measured denoting full cervical dilatation

face, with the measurement rounded up or down to the nearest hour (with $12.00 \mathrm{~h}$ representing the occiput anterior position).

TPUS was performed using a curved 2D $4.6 \mathrm{MHz}$ transducer (SONOACE R5) following each VE by another examiner where each examiner was blinded from the data recorded by the other. TPUS was done with the woman lying supine in the lithotomy position. Cervical dilatation was assessed in the sagittal view with the cursor placed on the inner part of the cervical tissue anteriorly and the inner part of the cervical tissue posteriorly (Figs. 1 and 2). Fetal head descent was assessed in a transverse view by measuring the fetal head perineal distance (HPD) in centimeters as the shortest distance between the outer bony limit of the fetal skull and the perineum (Figs. 3, 4, 5 and 6). Fetal head position was

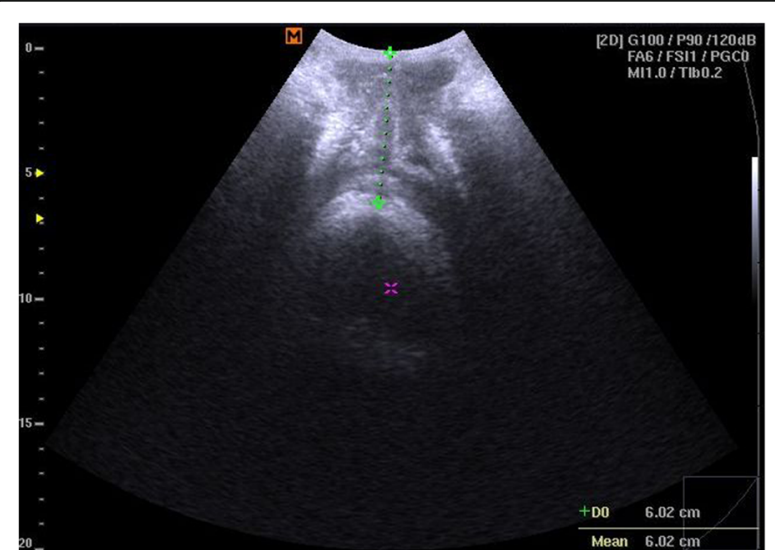

Fig. 3 Fetal head perineum distance. HPD is $6.02 \mathrm{~cm}$ rounded down to $6 \mathrm{~cm}$ measured transperineally in the transverse view from the outer bony limit of the fetal skull to the perineum 


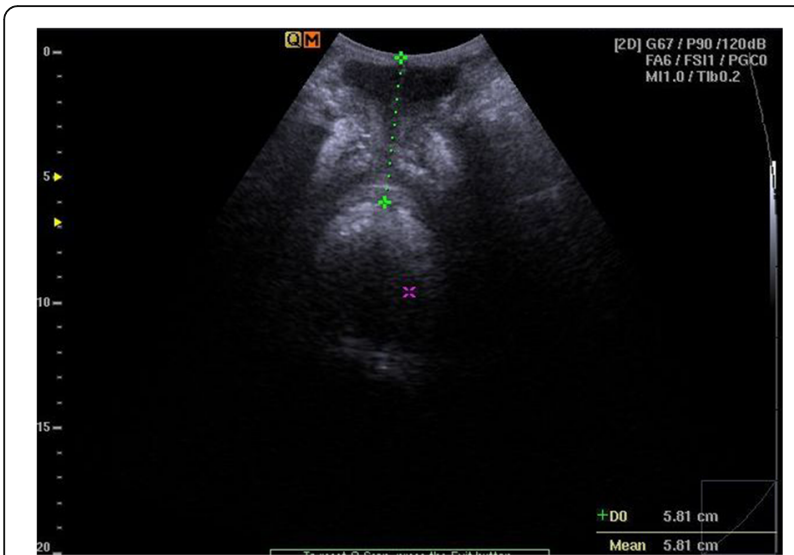

Fig. 4 Fetal head perineum distance (2). HPD is $5.81 \mathrm{~cm}$ rounded up to $6 \mathrm{~cm}$ measured by TPUS

defined by using the fetal spine or orbits as a landmark and the occiput as a denominator and was expressed according to a 12-h clock as for the digital VE (Fig. 7). Data obtained by TPUS was recorded on the sonopartogram first introduced by Hassan et al. (Fig. 8) [11].

The women received the standard care by the obstetrician where management of labor was based on the digital VE being blinded from the TPUS information. After delivery, the participants were asked which of the two methods of assessment was more satisfactory.

Data was analyzed using Stata ${ }^{\circ}$ version 14 (StataCorp LLC, College Station, TX, USA) and XLSTAT $\odot$ version 2014.5.03 (Addinsoft, Inc., Brooklyn, NY, USA). Normally distributed numerical data was presented as mean \pm SD and range, and skewed data as median and interquartile range. Categorical data was presented as number and percentage. Correlations were tested nonparametrically using the Spearman rank correlation or

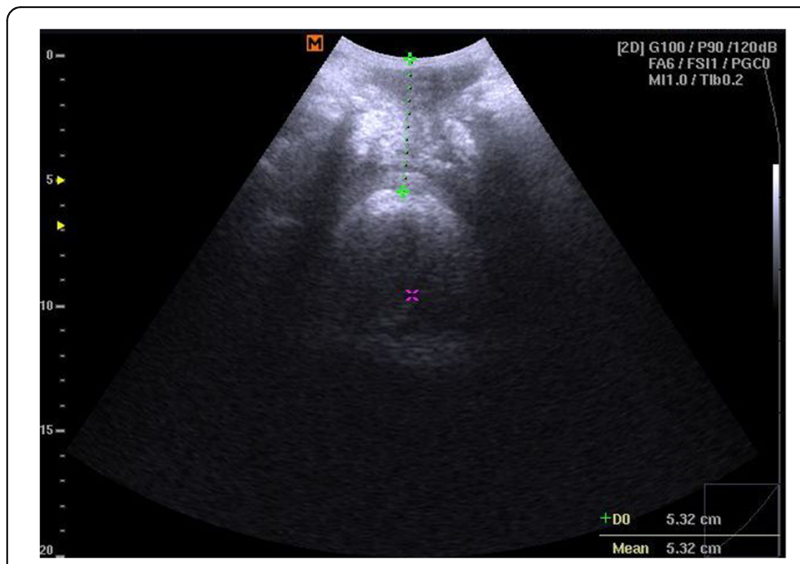

Fig. 5 Fetal head perineum distance (3). HPD is $5.32 \mathrm{~cm}$ rounded down to $5 \mathrm{~cm}$ measured by TPUS

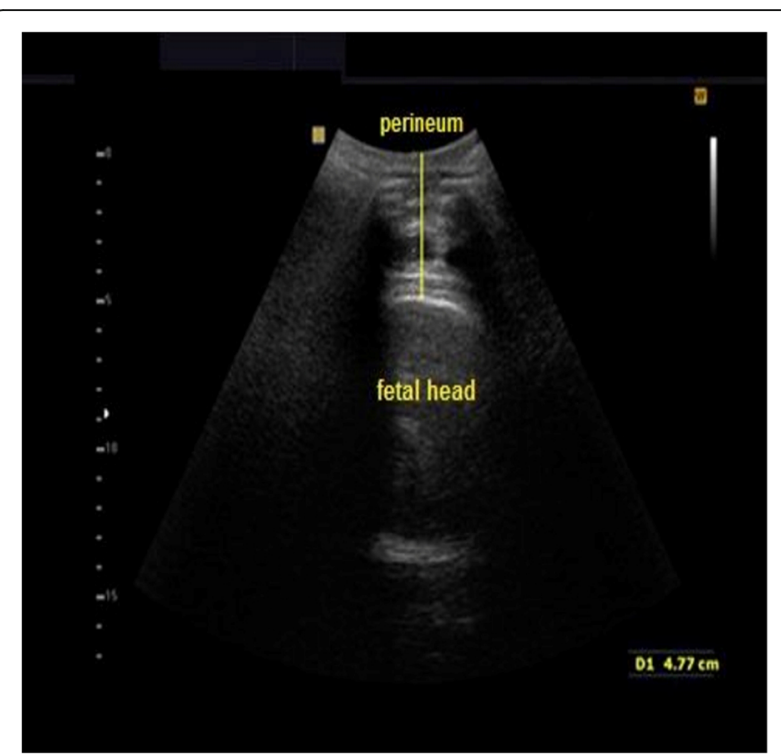

Fig. 6 Fetal head perineum distance (4). HPD is $4.77 \mathrm{~cm}$ rounded up to $5 \mathrm{~cm}$ measured by TPUS

Kendall's rank correlation. Bland-Altman method was used to examine agreement between US and VE as regards the quantification of cervical dilatation and head rotation. The differences between the two methods were plotted (on the $Y$-axis) against the averages of the two methods (on the $X$-axis). Horizontal lines were then drawn at the mean difference (bias), and at the limits of agreement, which are defined as the mean difference \pm 1.96 times the standard

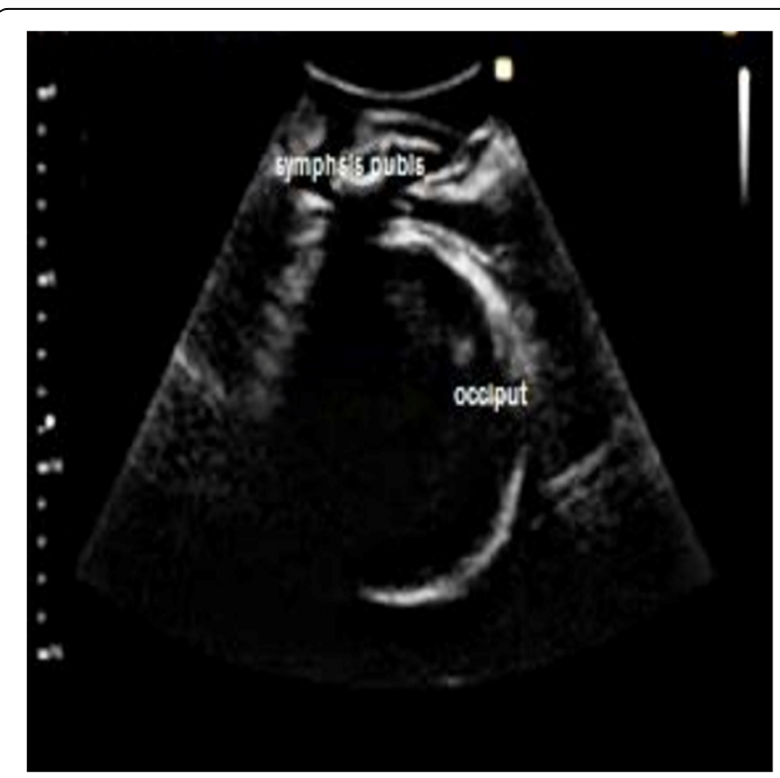

Fig. 7 Fetal head position 


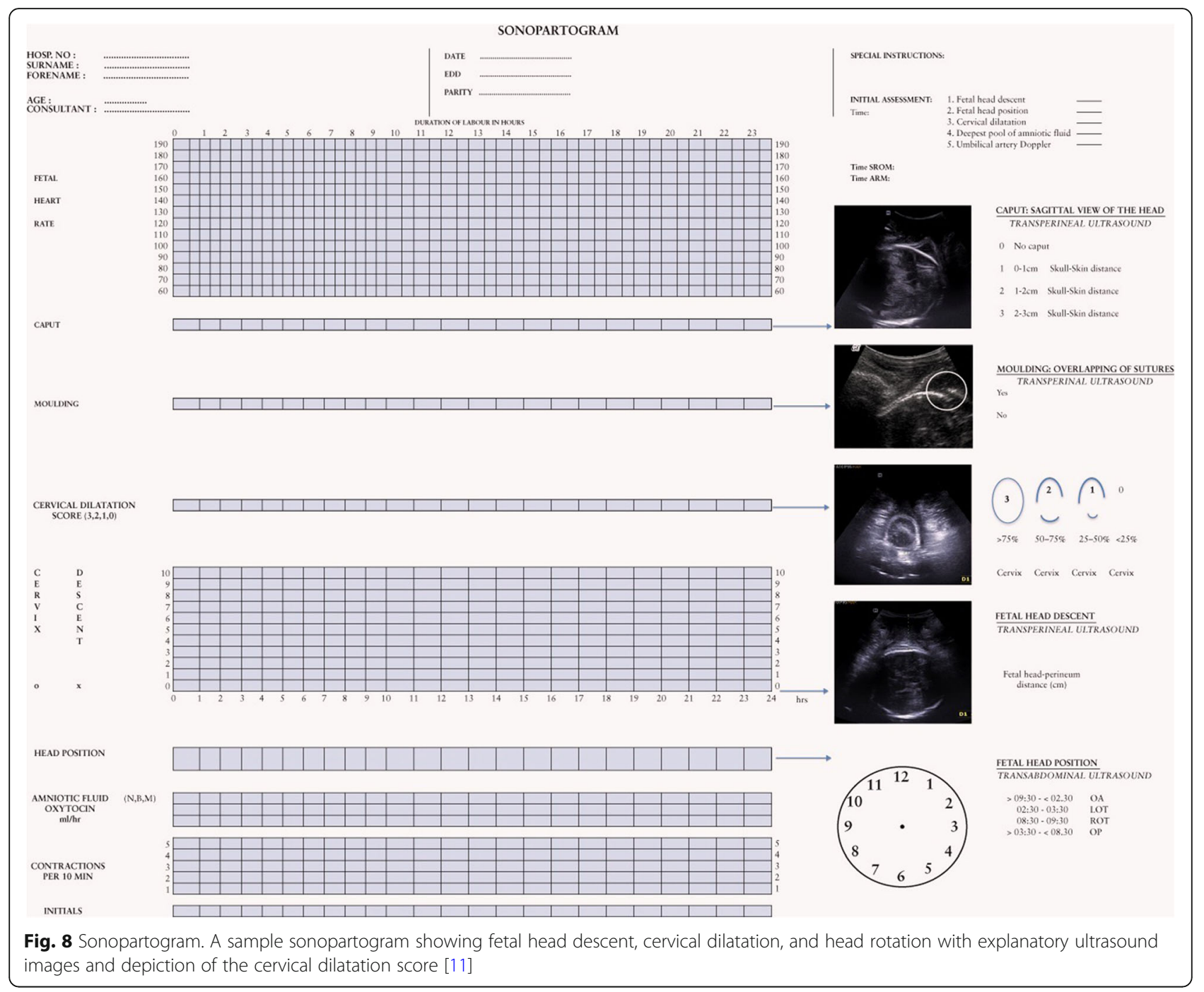

deviation (SD) of the differences. If the differences within mean $\pm 1.96 \mathrm{SD}$ (i.e., limits of agreement) are not clinically important, the two methods may be used interchangeably [14].

\section{Results}

A fair correlation was found between assessment of fetal head station by VE and fetal HPD by TPUS, (Kendall's tau-b $(\tau)=-0.299,95 \% \mathrm{CI}=-0.479$ to $-0.0863, p$ value $=.0063)$ (Fig. 9), (Spearman rho $=-.3844, p$ value $=$ $.0143 ; r^{2}=0.1478$ ] (Fig. 10). There is very strong correlation between the cervical dilatation assessed by VE and by US (Pearson's $r=.8601,95 \% \mathrm{CI}=0.7493$ to $0.9240, p$ value $\left.<.0001, r^{2}=0.7396\right)$. The mean difference between VE and US for assessment of cervical dilatation was $0.65 \pm 1.11 \mathrm{~cm}$. The limits of agreement were -1.52 to $2.82 \mathrm{~cm}$ (Fig. 11). The mean difference between VE and US for the assessment of fetal rotation on the face-clock was $-0.65 \pm 2.38 \mathrm{~h}$. The limits of agreement were -5.52 to $3.92 \mathrm{~h}$ on face-clock. There is moderate agreement between VE and US as regards the assessment of head position on the face-clock [weighted kappa $(\kappa)=.557,95 \% \mathrm{CI}=.362$ to.753] (Table 1 ). Women showed significantly more compliance and satisfaction towards TPUS 24/40 (60\%) than VE 14/40 $(35 \%), p$ value $=0.025$.

\section{Discussion}

Vaginal delivery could be a very distressing condition for many women, especially primigravida; indeed, repeated $\mathrm{VE}$ increases the inconvenience to them. This study shows that the use of TPUS for assessment of parameters such as cervical dilatation and fetal head descent and position is comparable to VE and can be used as an alternative especially in selected cases where VE is not desirable as premature rupture of membranes and 


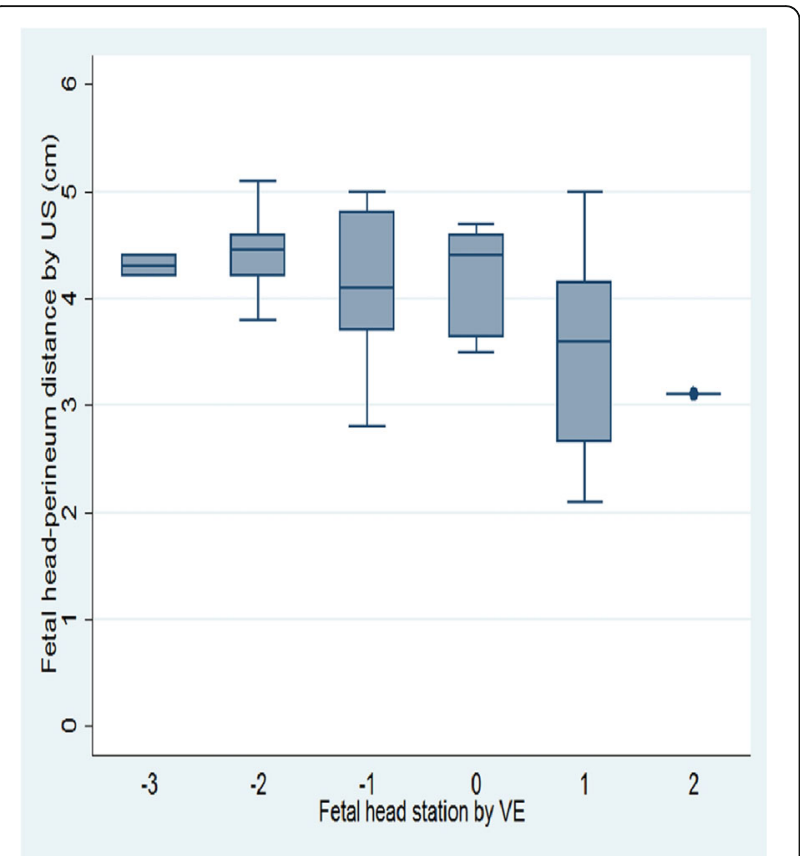

Fig. 9 Box plot showing relation between fetal head station by VE and fetal HPD by US. Box plot showing the relation between the fetal head station by VE and fetal head-perineum distance by US. The box represents the range from the first quartile to the third quartile (interquartile range). The line inside the box represents the median (second quartile). Error bars represent the minimum and maximum values. Kendall's tau-b $(\tau)=-0.299,95 \% \mathrm{Cl}=-0.479$ to $-0.0863, p$ value $=.0063$

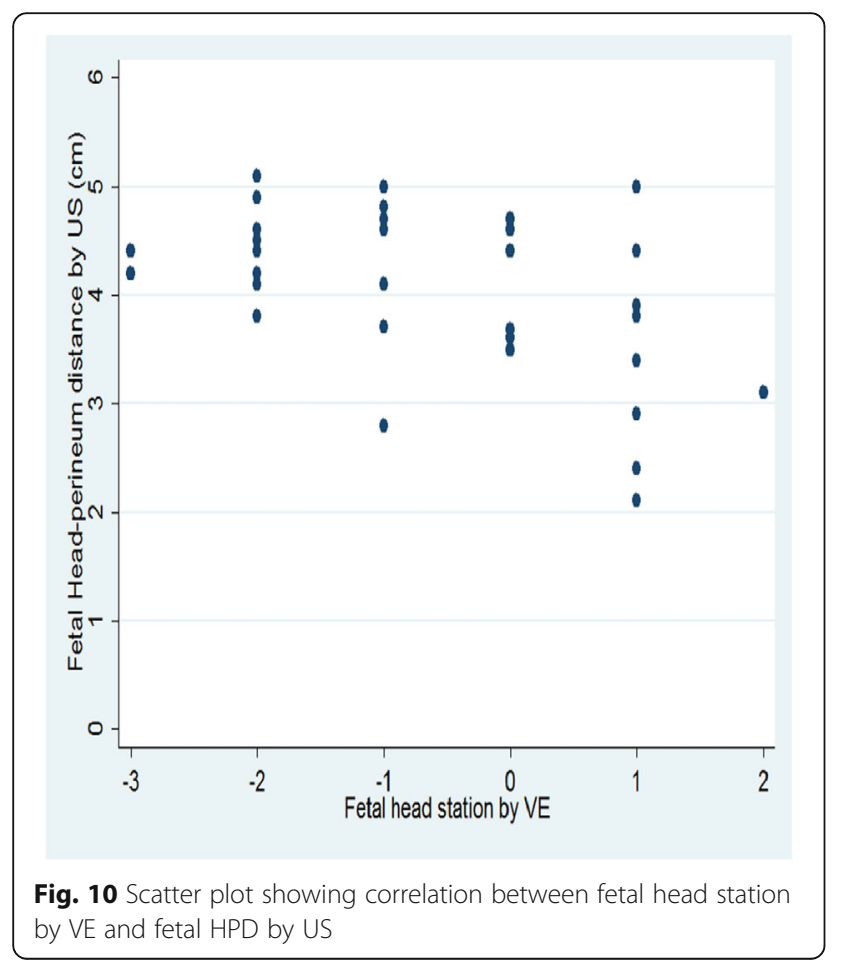

prolonged labor. There was a very strong correlation between VE and US for the assessment of cervical dilatation. Hassan et al. [11] suggested that VE tends to give larger estimates of cervical dilatation and explained this by the progressive nature of labor where US assessment preceded VE. Still, in this study VE, tends to show slightly larger estimates in spite being done before US examination; this proves the subjective nature of VE in contrast to US assessment which tends to be more objective. VE itself tends to cause overstretching of the cervix. Although estimation of cervical dilatation by US was found to be harder when the cervix is almost fully dilated, still, the mere presence of cervical tissue in US could exclude full cervical dilatation even when estimated so by VE.

Fetal head position showed moderate agreement between VE and US; several previous studies have suggested that US is even more accurate in the assessment of fetal head position than VE which might be altered by the presence of caput and even suggesting that the accuracy of VE did not improve with the increase of cervical dilatation [15-19]. Most of these studies compared fetal head position assessment by VE to transabdominal ultrasound. This study shows that assessment of head position by TPUS is feasible and with considerable accuracy.

Fetal head station assessment by TPUS has been studied using different methods of assessment including head-symphysis distance [20], angle of progression [21], and head-perineum distance (HPD) [22, 23]. This study chose the HPD for the easiness of the technique and previous experience with the technique [23]. HPD showed a moderate correlation with VE in the assessment of head station. The assessment of labor progress using TPUS has showed an overall more acceptance of women over repeated VE. The use of the sonopartogram introduced by Hassan et al. [11] allows even complete follow-up of women during labor and with comparable accuracy and convenience to the conventional partogram. The study had several strength points; the blinding of the VE and TPUS assessors decreases the bias of the results and allowed commencement of the study without interfering with the labor management. The choice of HPD might be considered as one of the merits of the study; the easiness of this technique makes this assessment tool easy to learn for most physicians and easy to be applied by almost any ultrasound machine. This study does not only provide an alternative assessment tool for assessing cervical dilatation and fetal head descent, but provide a whole assessment method of the progress of labor together with assessment of maternal and fetal condition using the sonopartogram. Still, the relatively small number of participants might be considered as a limitation to the study. 


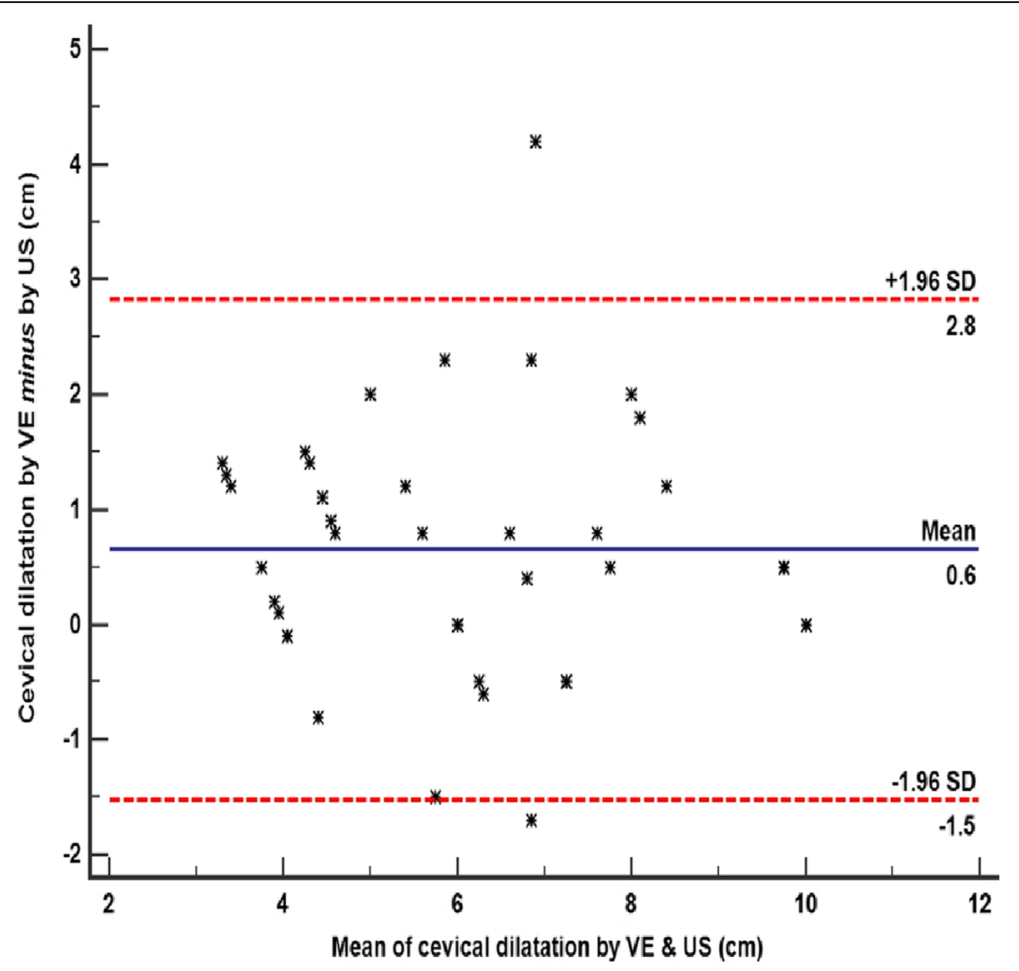

Fig. 11 Bland-Altman plot for agreement between VE and US as regards the assessment of cervical dilatation

Table 1 Agreement between VE and US as regards the assessment of head position on face-clock

\begin{tabular}{|c|c|c|c|c|c|c|c|c|c|c|c|c|c|}
\hline \multirow[b]{2}{*}{ Face-clock by US } & \multicolumn{11}{|c|}{ Face-clock by VE } & \multirow[b]{2}{*}{ Total N } & \multirow[b]{2}{*}{$\%$} \\
\hline & $1 \mathrm{~h}$ & $2 \mathrm{~h}$ & $3 \mathrm{~h}$ & $4 \mathrm{~h}$ & $5 \mathrm{~h}$ & $6 \mathrm{~h}$ & $7 \mathrm{~h}$ & $8 \mathrm{~h}$ & $9 \mathrm{~h}$ & $10 \mathrm{~h}$ & $12 \mathrm{~h}$ & & \\
\hline $1 \mathrm{~h}$ & 5 & 0 & 0 & 0 & 0 & 0 & 0 & 0 & 0 & 0 & 0 & 5 & $12.5 \%$ \\
\hline $2 \mathrm{~h}$ & 0 & 2 & 0 & 0 & 0 & 0 & 0 & 0 & 0 & 0 & 0 & 2 & $5 \%$ \\
\hline $3 \mathrm{~h}$ & 3 & 1 & 7 & 0 & 1 & 1 & 0 & 0 & 0 & 0 & 0 & 13 & $32.5 \%$ \\
\hline $4 \mathrm{~h}$ & 0 & 2 & 1 & 0 & 0 & 0 & 0 & 1 & 0 & 0 & 0 & 4 & $10 \%$ \\
\hline $5 \mathrm{~h}$ & 1 & 0 & 1 & 0 & 1 & 0 & 0 & 0 & 0 & 0 & 0 & 3 & $7.5 \%$ \\
\hline $6 \mathrm{~h}$ & 0 & 0 & 2 & 0 & 0 & 2 & 0 & 0 & 0 & 0 & 0 & 4 & $10 \%$ \\
\hline $7 \mathrm{~h}$ & 0 & 0 & 0 & 0 & 0 & 0 & 1 & 1 & 0 & 0 & 0 & 2 & $5 \%$ \\
\hline $8 \mathrm{~h}$ & 0 & 0 & 0 & 0 & 0 & 0 & 0 & 1 & 0 & 1 & 0 & 2 & $5 \%$ \\
\hline $9 \mathrm{~h}$ & 0 & 1 & 0 & 0 & 0 & 0 & 0 & 1 & 2 & 0 & 0 & 4 & $10 \%$ \\
\hline $10 \mathrm{~h}$ & 0 & 0 & 0 & 0 & 0 & 0 & 0 & 0 & 0 & 0 & 0 & 0 & $0 \%$ \\
\hline $12 \mathrm{~h}$ & 0 & 1 & 0 & 0 & 0 & 0 & 0 & 0 & 0 & 0 & 0 & 1 & $2.5 \%$ \\
\hline Total N & 9 & 7 & 11 & 0 & 2 & 3 & 1 & 4 & 2 & 1 & 0 & 40 & $100 \%$ \\
\hline$\%$ & $22.5 \%$ & $17.5 \%$ & $27.5 \%$ & $0 \%$ & $5 \%$ & $7.5 \%$ & $2.5 \%$ & $10 \%$ & $5 \%$ & $2.5 \%$ & $0 \%$ & $100 \%$ & \\
\hline \multicolumn{14}{|c|}{ Measure of agreement } \\
\hline Weighted $\mathrm{K}$ & \multicolumn{13}{|l|}{.557} \\
\hline SE & \multicolumn{13}{|l|}{0.1} \\
\hline $95 \% \mathrm{Cl}$ & \multicolumn{13}{|c|}{.362 to. 753} \\
\hline
\end{tabular}




\section{Conclusion}

Assessment of labor progress using transperineal ultrasound and the suggested sonopartogram can be an alternative to the conventional partogram especially when repeated VE is not desirable as in cases with prolonged labor, premature rupture of membranes, or patient non-compliance.

\section{Abbreviations}

HPD: Head-perineum distance; US: Ultrasound; TPUS: Transperineal ultrasound; VE: Vaginal examination

\section{Acknowledgements}

Ain Shams University.

\section{Authors' contributions}

MS helped design the study, supervised the undertaking of the trial, undertook the analysis, edited the final manuscript, and shared in funding the study. IA helped design the study, supervised the undertaking of the trial, undertook the analysis, wrote the first draft of the manuscript, and shared in funding the study. SA provided the detailed statistical advice during the design, supervised the undertaking of the trial, gave editorial feedback to versions of the manuscript, and shared in funding the study. OM helped design the study, shared in the undertaking of the trial, assisted with the data analysis, gave editorial feedback to versions of the manuscript, and shared in funding the study. EN shared in the undertaking of the trial, provided advice during the running of the trial, collected the data for analysis, gave editorial feedback to versions of the manuscript, and shared in funding the study. All authors read and approved the final manuscript.

\section{Funding}

The authors did not receive any external funding in the study.

\section{Availability of data and materials}

The datasets used and/or analysed during the current study are available from the corresponding author on reasonable request.

\section{Ethics approval and consent to participate}

This study was approved by the ethics committee of Ain Shams University with approval number AS1852. The participants provided written consent.

\section{Consent for publication}

All patients included in this research gave written informed consent to publish the data contained within this study.

\section{Competing interests}

The authors declare that they have no competing interests.

\section{Author details}

'Department of Obstetrics and Gynecology, Ain Shams University, Cairo, Egypt. ${ }^{2}$ Department of Obstetrics and Gynecology, Ahmed Maher Teaching Hospital, Cairo, Egypt. ${ }^{3}$ Department of Radiology, Helwan University, Cairo, Egypt.

Received: 26 May 2020 Accepted: 17 August 2020

Published online: 27 August 2020

\section{References}

1. Buchmann EJ, Libhaber E (2007) Accuracy of cervical assessment in the active phase of labour. BJOG. 114(7):833-837

2. Brubakear L, Wolfe AJ (2017) The female urinary microbiota, urinary health and common urinary disorders. Ann Transl Med. 5(2):34

3. Ying Lai C, Levy V (2002) Hong Kong Chinese women's experiences of vaginal examinations in labour. Midwifery. 18(4):296-303

4. Kathir V, Maurya D, Keepanasseril A (2018) Transvaginal sonographic assessment of cervix in prediction of admission to delivery interval in preterm premature rupture of membranes. J Matern Fetal Neonatal Med. 31(20):2717-2720
5. National Institute for Health and Clinical Excellence (NICE) Clinical guideline [CG190] (2017). Intrapartum care for healthy women and babies. https:// www.nice.org.uk/guidance/cg190.

6. Ghi T, Eggebø T, Lees C, Kalache K, Rozenberg P, Youssef A, Salomon LJ, Tutschek B (2018) ISUOG Practice Guidelines: intrapartum ultrasound. Ultrasound Obstet Gynecol. 52(1):128-139

7. Hassan WA, Eggebø TM, Ferguson M, Lees C (2013) Simple two-dimensional ultrasound technique to assess intrapartum cervical dilatation: a pilot study. Ultrasound Obstet Gynecol. 41(4):413-418

8. Pérez SP, Seguer JJ, Pujadas AR, Azuara LS, Juanos JL, Sagristà OA (2017) Role of intrapartum transperineal ultrasound: angle of progression cut-off and correlation with delivery mode. Clin Obstet Gynecol Reprod Med. 3(4):1-4

9. Ramphul M, Kennelly M, Murphy DJ (2012) Establishing the accuracy and acceptability of abdominal ultrasound to define the foetal head position in the second stage of labour: a validation study. Eur J Obstet Gynecol Reprod Biol. 164(1):35-39

10. Tutschek B, Braun T, Chantraine F, Henrich W (2011) A study of progress of labour using intrapartum translabial ultrasound, assessing head station, direction, and angle of descent. BJOG. 118(1):62-69

11. Hassan WA, Eggebø T, Ferguson M, Gillett A, Studd J, Pasupathy D, Lees CC (2014) The sonopartogram: a novel method for recording progress of labor by ultrasound. Ultrasound Obstet Gynecol. 43(2):189-194

12. Solaiman SA, Atwa KA, Gad AA, Al-Shatouri M (2020). Egyptian Journal of Radiology and Nuclear Medicine. 51:94.

13. World Health Organization partograph in management of labour (1994) World Health Organization Maternal Health and Safe Motherhood Programme. Lancet. 343(8910):1399-1404

14. Bland JM, Altman DG (2007) Agreement between methods of measurement with multiple observations per individual. J Biopharm Stat. 17(4):571-582

15. Akmal S, Kametas N, Tsoi E, Hargreaves C, Nicolaides KH (2003) Comparison of transvaginal digital examination with intrapartum sonography to determine fetal head position before instrumental delivery. Ultrasound Obstet Gynecol. 21(5):437-440

16. Akmal S, Tsoi E, Kametas N, Howard R, Nicolaides KH (2002) Intrapartum sonography to determine fetal head position. J Matern Fetal Neonatal Med. 12(3):172-177

17. Sherer DM, Miodovnik M, Bradley KS, Langer O (2002) Intrapartum fetal head position I: comparison between transvaginal digital examination and transabdominal ultrasound assessment during the active stage of labor. Ultrasound Obstet Gynecol. 19(3):258-263

18. Sherer DM, Miodovnik M, Bradley KS, Langer O (2002) Intrapartum fetal head position II: comparison between transvaginal digital examination and transabdominal ultrasound assessment during the second stage of labor. Ultrasound Obstet Gynecol. 19(3):264-268

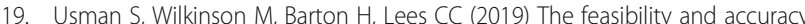
of ultrasound assessment in the labor room. J Matern Fetal Neonatal Med. 32(20):3442-3451

20. Youssef A, Maroni E, Ragusa A, De Musso F, Salsi G, lammarino MT, Paccapelo A, Rizzo N, Pilu G, Ghi T (2013) Fetal head-symphysis distance: a simple and reliable ultrasound index of fetal head station in labor. Ultrasound Obstet Gynecol. 41(4):419-424

21. Dückelmann AM, Bamberg C, Michaelis SA, Lange J, Nonnenmacher A, Dudenhausen JW, Kalache KD (2010) Measurement of fetal head descent using the 'angle of progression' on transperineal ultrasound imaging is reliable regardless of fetal head station or ultrasound expertise. Ultrasound Obstet Gynecol. 35(2):216-222

22. Eggebø TM, Heien C, Okland I, Gjessing LK, Smedvig E, Romundstad P, Salvesen KA (2008) Prediction of labour and delivery by ascertaining the fetal head position with transabdominal ultrasound in pregnancies with prelabour rupture of membranes after 37 weeks. Ultraschall Med. 29(2):179-183

23. El-Bishry GA, El Kholy AG, Sweed MS, Hassan N (2020) The accuracy of fetal head to perineum distance and cervical length in predicting the outcomes of labor induction. EBWHJ 10(1):16-26

\section{Publisher's Note}

Springer Nature remains neutral with regard to jurisdictional claims in published maps and institutional affiliations. 